\title{
Effect of fungal, oomycete and nematode interactions on apple root development in replant soil
}

Emma L. Tilston, Gregory Deakin, Julie Bennett, Thomas Passey, Nicola Harrison, Felicidad Fernández and Xiangming $\mathrm{Xu}^{*}$ (D)

\begin{abstract}
Background: Apple replant disease (ARD) is a phenomenon associated with poor tree establishment at sites where the same, or a closely-related species, has grown for at least 1-2 years. No single organism has been identified as the universal causal agent, but there is increasing evidence that multiple soil-borne plant pathogenic fungi and oomycetes form an ARD disease complex. Root damage caused by root lesion nematodes has also been implicated in facilitating the entry of pathogens into root tissues resulting in the development of severe ARD.

Methods: We used a reductionist approach to determine effects of one or more members of the ARD complex on ARD in a number of selected rootstock genotypes with contrasting characteristics. Through a 15-month pot-based experiment in which semi-selective biocides were applied to soil from a replant orchard, we investigated (1) the nature of the interactions (i.e. antagonistic, additive or synergistic) between different groups of soil biota and ARD severity, and (2) whether rootstock characteristics modify ARD severity.
\end{abstract}

Results: There might be competitive interactions between oomycetes and fungal pathogens in infecting apple roots and hence subsequent ARD development. Controlling all three ARD components (oomycetes, fungi, and nematodes) led to the best root development. However, these effects on root development were not manifested in the aboveground tree development 15 months after treatment. Specific soil biocide treatments against fungi and oomycetes led to large changes in soil microbial communities whereas the nematicide treatment led to least changes. In spite of the observed ARD, comparing rhizosphere microbial sequences among treatments failed to reveal candidate pathogens for ARD.

Conclusions: Candidate ARD oomycetes and fungal pathogens are likely to engage in competitive interactions among themselves in infecting apple roots. Although soil amendments affected soil microbiota, such effects appear to be very unpredictable.

Keywords: Competition, Oomycetes, Fungi, Root infection, Amplicon-sequencing

\section{Introduction}

Poor establishment of apple trees (Malus pumila Miller) at sites where the same, or a closely-related species, has grown for at least 1-2 years is a world-wide

*Correspondence: Xiangming.Xu@emr.ac.uk

NIAB EMR, New Road, East Malling, West Malling, Kent ME19 6BJ, UK problem affecting the production of both rootstocks and fruit trees (Mazzola and Manici 2012). Symptoms of apple replant disease (ARD) include uneven growth, stunting and shortened internodes aboveground, and discoloured roots, root tip necrosis and reduced root biomass belowground. The bearing of fruit is delayed by $2-3$ years and yields are depressed by up to nearly $60 \%$ 
for the duration of the tree's commercial life (Willett et al. 1994). Studies with pasteurized soil have demonstrated that the activity of the causal agent(s) is destroyed by heat, but the addition of as little as $10 \%$ conducive (untreated) soil to pasteurized soil can reinstate replant disease; thus, predominantly biotic factors have been identified as the underlying cause (Tewoldemedhin et al. 2011a, b, c). No single organism has been identified as the universal causal agent, but there is increasing evidence that multiple soil-borne plant pathogenic fungi (e.g. Cylindrocarpon spp. and Rhizoctonia spp.) and oomycetes (e.g. Phytophthora spp. and Pythium spp.) form a disease complex of variable species composition (Mazzola and Manici 2012). Root damage caused by root lesion nematodes (e.g. Pratylenchus penetrans Cobb) has also been implicated in facilitating the entry of pathogens into root tissues resulting in the development of severe ARD (Mai and Abawi 1978; Mazzola et al. 2009; Merwin and Stiles 1989; Dullahide et al. 1994). Diminished soil fertility, degraded soil structure and residual herbicide activity are all abiotic factors that, as well as inducing similar perturbations to plant growth, can exacerbate the effects of biotically-mediated replant disease (Mazzola and Manici 2012).

Strategies for managing ARD are generally based on the principles of exclusion or environmental alteration, with the aim of modifying the pathogenic and nonpathogenic components of the indigenous soil microbial community. Crop rotation, for example, exploits the natural decline in pathogen propagule viability occurring in the absence of a susceptible host as a means of reducing disease severity. Although rotation offers an effective means of reducing the severity of some diseases of annual crops, it is a less practical option for perennial crops (Mazzola and Gu 2000). Unlike many other soilborne diseases ARD shows limited spread in soil, with the result that trees replanted into the soil of the former aisle (typically planted with grass) are less affected by ARD (Rumberger et al. 2004). However, the spatial arrangement of rows and aisles in contemporary highdensity planting systems is rarely coincident with those of the older, traditional arrangements they replace, which compromises the utility of this strategy in commercial orchards. Since the 1950s the use of broad-spectrum pre-plant fumigants has been the most common means of achieving effective control of ARD around the world (Utkhede and Smith 2000). However, there is an increasing need for alternative management strategies because environmental and human health concerns regarding the use of soil fumigants with a broad spectrum of activity, including methyl bromide, metam sodium and chloropicrin, have resulted in national and international legislation to prohibit or severely restrict their use. Current research efforts are focused on more selective approaches for the modification of indigenous soil microbial communities e.g. the addition of antagonistic and beneficial microorganisms (Utkhede and Smith 2000; Hoitink and Boehm 1999), incorporation of composted organic amendments and their indigenous suppressive microbial communities (Yao et al. 2006) and specific orchard groundcover management regimes (St. Laurent 2008). Biofumigants, especially brassica seed meals (Mazzola et al. 2009; Mazzola and Manici 2012), appear to offer reproducible reductions in the populations of ARD causal agents and ARD disease severity. This is particularly true against $P$. penetrans: application of $B$. juncea seed meal resulted in more than $98 \%$ reduction in populations of $P$. penetrans. However, their principal market as biofuels and oils are likely to constrain biofumigant availability, and hence their wider adoption as a pre-planting treatment for replant sites. A better understanding of ARD biology, specifically the interactions within the microbial community, would aid the design and development of other strategies for ARD management.

Apples are extremely heterozygous and do not reproduce true-to-type from seed, so for commercial production they are clonally propagated by grafting a scion (shoot) onto a rootstock (root system plus a portion of lower stem) of another genotype. Rootstocks are chosen based on attributes conferred onto the scion and the fruit it produces such as tolerance of less than optimal soil conditions, fruit size, precocity, productivity, disease and insect resistance and tree vigour (Russo et al. 2007). Dwarfing (M.9) rootstocks that severely restrict the size of the scion have found particular use in high density planting systems for dessert apples. The semivigorous rootstock MM.106 is typically used to produce cider apple trees, but is highly susceptible to ARD (Auvil et al. 2011) and other soil-borne diseases (Mazzola et al. 2009). M.116 is slightly less vigorous than MM.106, but is reportedly resistant to ARD and other diseases (clone 86.1.25 in Websteret al. 1986). The planting of resistant apple rootstock genotypes has proven to be an effective means of reducing the severity of Phytophthora crown and root rots and in principle is an attractive option for managing ARD. Since 2003 the USDA-ARS/Cornell University National Apple Rootstock Breeding Program has been conducting rootstock trials under modern, high density systems at sites harbouring ARD. As a result of these trials some of the Cornell-Geneva rootstocks e.g. G.41 have been reported to show greater tolerance of ARD than other rootstocks (Isutsa and Merwin 2000; Mazzola et al. 2009), notably the current commercial standard for dessert apple M.9. Surprisingly, despite the reported variation in susceptibility/tolerance to ARD, the 
interactions between rootstock genotypes and ARD complex composition remain poorly understood.

In this study, a reductionist approach was used to study the root-pest/pathogen relationships for individual members of the complex and the responses of rootstock genotypes with contrasting traits. Through a 15-month pot-based experiment in which semi-selective biocides were applied to soil from a replant orchard we investigated (1) the nature of the interactions (i.e. antagonistic, additive or synergistic) between different groups of soil biota and ARD severity, and (2) whether rootstock characteristics modify ARD severity. As (all) the exact causal agents for ARD are not known for any given sites, we did not attempt to quantify/isolate candidate ARD causal organisms in the experimental soil or to inoculate soils with candidate organisms as this was not absolutely necessary for the present study objective. The key assumption we made was that the experimental soils contained some or all ARD causal organisms. For the same reason, we cannot be certain that the biocides we used would be able to eliminate all ARD casual agents; the efficacy of such biocide treatments and/or the relative importance of different ARD components could, however, be reflected in the severity of visually assessed ARD symptoms.

\section{Materials and methods}

\section{Experimental factors and study design}

The experiment consisted of a factorial design to study the effects of rootstock genotypes and soil biocide treatments on tree development. There were four rootstock genotypes: (1) M.9 (dwarfing, ARD susceptible), (2) G.41 (dwarfing, very ARD tolerant), (3) M.M.106 (semivigorous, partially ARD tolerant), and (4) M.116 (semivigorous, ARD tolerant). Proprietary chemicals (specific biocides) were applied to the soil to reduce or eliminate specific candidate ARD components: fungal and oomycete pathogens and nematodes. There were four biocide treatments in which (1) nematodes [Nematicide], (2) both nematodes and oomycetes [Nem_Oom], (3) both nematodes and fungi [Nem_Fun], and (4) all three components (nematodes, oomycetes and fungi) were controlled [Nem_Oom_Fun]. In addition, untreated soil acted as the control treatment. Thus, as per Additional file 1: Table S1, there were a total of 20 conditions ( 4 genotypes $\times 5$ biocide treatments), each with six replicates (potted trees). A randomised block design with six blocks was used: with one replicate per treatment in each block.

\section{Soil}

In March 2016 soil was obtained from a 'replant' orchard site with an 80-year history of apple growing located at the NIAB EMR demonstration farm in mid
Kent $(51.288 \mathrm{~N}, 0.455 \mathrm{E})$. The orchard was planted to 28-year-old trees of dessert apple cultivars 'Fiesta' and 'Temptation' grafted on M.9 rootstocks, and had a history of poor tree performance and reduced yields attributed to ARD. The soil was collected from a depth of 0 to $20 \mathrm{~cm}$ depth in a $1.5 \mathrm{~m}$ zone around the trunks of the apple trees (Horner and Wilcox 1996). The soil was a well-drained, non-calcareous chromic Luvisol (FAO and IUSS 2015) of the Fyfield series (Furneaux 1954), with sandy loam texture (61\% sand, $26 \%$ silt and $13 \%$ clay) and the following physico-chemical characteristics: $\mathrm{pH}$ (1:2.5 $\mathrm{w} / \mathrm{v}$, water $)=6.1 \pm 0.15,17.5 \pm 1.15 \mathrm{mg}$ organic $\mathrm{C} \mathrm{g}^{-1}$ soil, $1.6 \pm 0.18 \mathrm{mg} \mathrm{N} \mathrm{g}^{-1}$ soil, $39.5 \pm 2.12 \mathrm{mg}$ extractable $\mathrm{P} \mathrm{kg}{ }^{-1}$ soil, $281 \pm 4.6 \mathrm{mg}$ extractable $\mathrm{K} \mathrm{kg}^{-1}$ soil and $101 \pm 5.3 \mathrm{mg}$ extractable $\mathrm{Mg} \mathrm{kg}^{-1}$. Fresh plant debris, stones and macrofauna were removed from composited soil by hand-sorting prior to homogenisation by sieving $(10 \mathrm{~mm})$ in the field-moist state. Sieved soil was stored at ambient temperature for not more than four weeks prior to the incorporation of $0.4 \%(\mathrm{w} / \mathrm{v})$ slow release fertilizer (elemental composition: $15 \% \mathrm{~N}, 3.9 \% \mathrm{P}, 9.1 \% \mathrm{~K}, 1.2 \% \mathrm{Mg}$, $0.45 \% \mathrm{Fe}, 0.06 \% \mathrm{Mn}, 0.02 \% \mathrm{~B}, 0.05 \% \mathrm{Cu}, 0.02 \% \mathrm{Mo}$ and $0.015 \% \mathrm{Zn}$ ) and the application of biocides.

\section{Biocides}

Proprietary biocides were applied to the soil in square, $3 \mathrm{~L}$ capacity polypropylene pots to control specific ARD components: (1) oxamyl granules (Vydate 10G, Corteva Agriscience, Cambridge, UK) (12.0 mg a.i. per litre of soil) against nematodes, (2) fenamidone + fosetyl-aluminium (Fenomenal, Bayer Crop Science UK, Cambridge, UK) (9 $\mathrm{mg}+90 \mathrm{mg}$ a.i. per litre of soil, respectively) against oomycetes, (3) prochloraz (Octave, Fargro, Arundel, UK) (460 $\mathrm{mg}$ a.i. per litre of soil) and tolclofos-methyl (Basilex, The Scotts Company (UK) Ltd, Ipswich, UK) (50 mg a.i. per litre of soil) against ascomycete and basidiomycete fungi. Fosetyl-aluminium is known be effective against a number of Pythium spp. (Weiland, Santamaria, and Grünwald 2014). Prochloraz is effective against a range of fungal pathogens, including Fusarium spp. and tolclofosmethyl is effective against Rhizoctonia spp. among other pathogens. Appropriate combinations of these products were used to achieve the Nem_Oom, Nem_Fun, and Nem_Oom_Fun treatments. Residual phytotoxicity from the biocide treatments was tested ten days after the application of biocides by sowing seeds of garden cress (Lepidium sativum L.) in five randomly selected pots from the 24 pots in receipt of each biocide treatment and the untreated control. Within 5 days the seeded pots had a dense sward of cress seedlings, which displayed none of the typical signs of phytotoxicity; likewise, the unsown pots supported numerous weed seedlings from the indigenous seedbank. 


\section{Planting material}

One-year old rootstocks of the four genotypes were obtained from commercial nurseries. Between 40 and 60 rootstocks of each genotype were grafted with cv. 'Gala' and placed in $4.5 \mathrm{~cm} \times 4.5 \mathrm{~cm} \times 20 \mathrm{~cm}$ hinged modular cells containing a 1:3 volumetric mixture of autoclaved sandy loam soil and compost, plus $0.4 \%$ $(\mathrm{w} / \mathrm{v})$ slow release fertilizer and grown under protected conditions for 8 weeks. After removal of grafting tape and wax, reference marks $5.5 \mathrm{~cm}$ below and above the graft union were made with gloss paint and rootstock and scion diameter determined at these marks enabling the selection of 30 apparently healthy trees of reasonably uniform size (8-10 $\mathrm{mm}$ diameter rootstock and 6-8 $\mathrm{mm}$ diameter scion) from each rootstock genotype for use in the experiment.

\section{Plant maintenance}

Selected trees were transplanted into $5 \mathrm{~L}$ pots of untreated and biocide-treated soil as required and between July and mid-December 2016 were grown under protected conditions in a polytunnel with open sides. To induce winter dormancy, the trees were moved to a sheltered position outside in mid-December 2016 and at the end of May 2017, they were returned to the polytunnel until the final assessment in September 2017. Irrespective of location, to ensure that the pots were free-draining and to minimize cross contamination, the pots were raised $16 \mathrm{~cm}$ above the ground on slatted staging. While in the polytunnel the trees received variable amounts of fertigation according to the prevailing temperatures, but outside they were rain-fed over winter and manually watered after bud burst. Fruit production was prevented by manual removal of flowers and similarly, weeds and tortrix moth caterpillars were also removed by hand. Between June and September, the trees received a 4-weekly program of proprietary fungicide and insecticide sprays to control powdery mildew [Podosphaera leucotricha (Ellis \& Everh.) E.S. Salmon], aphids [e.g. Dysaphis plantaginea (Passerini)] and white fly (Trialeurodes vaporariorum Westwood). Additional file 1: Table S2 gives the monthly summary of temperature and relative humidity during the entire experimental period.

\section{Plant assessments}

Tree growth was assessed by measuring rootstock and scion diameters and girths at the reference marks $5.5 \mathrm{~cm}$ below and above the graft union, shoot height from the graft union, and the number and length of individual branches. The trees were excised into 'shoots' (above the graft union), 'rootstock trunk' (below the graft union), 'roots' and 'galls' and dried to constant mass at $80{ }^{\circ} \mathrm{C}$ after visual assessment of the roots. Root health was rated using ordinal scales for: (i) necrosis $[0=$ no obvious necrosis, $1 \leq \%$ roots necrotic, $2=25$ to $50 \%$ roots necrotic, $3=50$ to $75 \%$ roots necrotic and $4=75$ to $100 \%$ roots necrotic, plant death (Tewoldemedhin, Mazzola, Mostert, et al. 2011a, b, c; Tewoldemedhin, Mazzola, Botha, et al. 2011a, b, c)]; (ii) lateral root abundance [ $0=$ very few lateral roots, $1=$ sparse abundance of lateral roots, $2=$ moderate abundance of lateral, $3=$ lateral roots abundant and $4=$ lateral roots very abundant (St. Laurent et al. 2010)]; and iii) crown gall (Rhizobium radiobacter Beijerinck and van Delden) severity $[0=$ no galling, $1=$ small galls on lateral roots only, $2=$ galls $<2.5 \mathrm{~cm}$ diameter on rootstock, $3=$ galls 2.5 to $5 \mathrm{~cm}$ diameter on rootstock and $4=$ galls $>5 \mathrm{~cm}$ diameter on rootstock (Moriya et al. 2008)].

\section{Soil microbial and nematode community profiling}

The diversity and composition of bacterial, fungal, oomycete and nematode communities in the rhizosphere soil collected on termination of the experiment was determined by amplicon sequencing. Rhizosphere soil was operationally defined as the soil adhering to roots after removal of the root system from soil followed by gentle shaking.

Amplicon sequencing and sequence processing followed the method used previously (Deakin et al. 2018). Briefly, genomic DNA was extracted from rhizosphere soil samples using the DNeasy PowerSoil Kit (Qiagen, Carlsbad, USA) in conjunction with a bead beating benchtop homogenizer (Fastprep FP120, Qbiogene, Carlsbad, USA). The following regions and primer pairs were used for PCR amplification; (1) for bacteria the $16 \mathrm{~S}$ V4 region was amplified using primer pair Bakt_341F/ Bakt_805R (Herlemann et al. 2011), (2) for fungi the ITS1 and ITS2 regions were amplified using primer pair EkITS1F/Ek28R(=3126 T) (Gardes and Bruns 1993; Sequerra et al. 1997), (3) for oomycetes the ITS1 region was amplified using primer pair ITS6 Forward/ITS7 Reverse (White et al. 1990; Cooke and Duncan 1997) and (4) for nematodes a fragment of the $18 \mathrm{~S}$ rDNA gene was amplified using primer pair nem18sF/nem18sR (Floyd et al. 2005). Nextera transposase adapters (Illumina, San Diego, USA) were appended to each amplicon. PCR conditions for each reaction are given in Table 1. All PCR reactions were performed in $25 \mu \mathrm{L}$ reaction mixtures comprising $1 \times \mathrm{PCR}$ buffer containing $2 \mathrm{mM} \mathrm{MgCl}_{2}$ and $1 \mathrm{U}$ Platinum Taq DNA Polymerase (Invitrogen, Life Technologies, Carlsbad, USA), $0.2 \mathrm{mM}$ dNTP (Fisher Bioreagents, Thermo Fisher Scientific, Pittsburgh, USA), $0.2 \mathrm{mM}$ forward and reverse primers each (Integrated DNA Technologies, Coralville, USA), 8 ng template DNA and molecular biology reagent water (Sigma, St Louis, USA). Amplicons for each marker region were cleaned using solid phase reversible immobilization beads (Agencourt XP Ampure beads; Beckman Coulter, Brea, USA), 
Table 1 PCR conditions used for each target group of soil biota

\begin{tabular}{|c|c|c|c|c|}
\hline \multirow[t]{2}{*}{ PCR step } & \multicolumn{4}{|l|}{ Target group (marker region) } \\
\hline & Bacteria (16S, V4 region) & $\begin{array}{l}\text { Fungi (18S, ITS1 and } 2 \\
\text { regions) }\end{array}$ & $\begin{array}{l}\text { Oomycetes (18S, ITS1 } \\
\text { region) }\end{array}$ & $\begin{array}{l}\text { Nematode (18S small } \\
\text { subunit) }\end{array}$ \\
\hline Initial denaturation & $95^{\circ} \mathrm{C}, 5 \mathrm{~min}$ & $95^{\circ} \mathrm{C}, 5 \mathrm{~min}$ & $95^{\circ} \mathrm{C}, 5 \mathrm{~min}$ & $95^{\circ} \mathrm{C}, 5 \mathrm{~min}$ \\
\hline No. PCR cycles & 25 & 30 & 15 & 30 \\
\hline Denaturation & $94^{\circ} \mathrm{C}, 30 \mathrm{~s}$ & $94^{\circ} \mathrm{C}, 30 \mathrm{~s}$ & $94^{\circ} \mathrm{C}, 30 \mathrm{~s}$ & $94^{\circ} \mathrm{C}, 45 \mathrm{~s}$ \\
\hline Annealing & $52^{\circ} \mathrm{C}, 60 \mathrm{~s}$ & $55^{\circ} \mathrm{C}, 60 \mathrm{~s}$ & $52{ }^{\circ} \mathrm{C}, 60 \mathrm{~s}$ & $57^{\circ} \mathrm{C}, 45 \mathrm{~s}$ \\
\hline Elongation & $72{ }^{\circ} \mathrm{C}, 60 \mathrm{~s}$ & $72{ }^{\circ} \mathrm{C}, 60 \mathrm{~s}$ & $72{ }^{\circ} \mathrm{C}, 60 \mathrm{~s}$ & $72^{\circ} \mathrm{C}, 90 \mathrm{~s}$ \\
\hline Final elongation & $72^{\circ} \mathrm{C}, 7 \mathrm{~min}$ & $72^{\circ} \mathrm{C}, 7 \mathrm{~min}$ & $72^{\circ} \mathrm{C}, 7 \mathrm{~min}$ & $72^{\circ} \mathrm{C}, 7 \mathrm{~min}$ \\
\hline
\end{tabular}

quality checked using a spectrophotometer (Nanodrop 1000, Thermo Fisher Scientific, Cambridge, UK) and a fluorometer (Qubit 2.0, Life Technologies, Carlsbad, USA) and pooled by individual sample. A Nextera XT DNA Library Preparation Kit (Illumina) was used to prepare and barcode amplicon libraries for sequencing with a MiSeq sequencer (Illumina) using $2 \times 300 \mathrm{bp}$ v3 reagent kits (Illumina). All kits were used according to the manufacturers' protocols.

\section{Sequence read processing}

FASTQ reads were demultiplexed into bacterial 16S, fungal (ITS), oomycete (ITS) and nematode (18S) datasets based on their primer sequences. Reads with non-matching forward and reverse primers were discarded before the sequences were processed in two stages. Firstly, sequences with any ambiguous positions in the primer region were removed and the resultant sequences filtered with very stringent criteria to generate an operational taxonomic unit (OTU) and to obtain the representative sequence for each OTU. In the second step, an OTU table (frequency of each OTU in each sample) was generated by filtering all sequences with far less stringent criteria and then aligning them with the OTU representative sequences. All analyses were performed using USEARCH 10.0 (Edgar 2013), unless specified otherwise.

\section{OTU generation}

Oomycete ITS forward and reverse reads were merged with a maximum difference in overlap of $10 \%$ and the forward and reverse primers removed. Merged reads containing adapter contamination or fewer than 150 nucleotides (NT) were excluded from further analysis. Remaining merged reads were filtered for quality with a maximum expected error threshold of 0.5 per sequence (Edgar and Flyvbjerg 2015). Bacterial $16 \mathrm{~S}$ reads were processed similarly, but with a maximum difference in overlap set to $5 \%$ and minimum size set to 300 NT.
The expected distance between fungal ITS and nematode $18 \mathrm{~S}$ primers was larger than twice the MiSeq read length. Consequently, forward and reverse reads could not be merged; only the forward reads were used and were treated as unpaired reads. Unpaired reads which contained either both forward and reverse primers, or the adapter sequence, were excluded from analysis. Additionally, for nematodes (due to either non-specific amplification of prokaryote DNA or reads which are unidentifiable) read pairs were merged (with a maximum $15 \%$ difference in overlap) and none merging forward reads retained. Reads shorter than 200 NT for fungal and $150 \mathrm{NT}$ for nematode were discarded. After removal of forward primers reads were quality filtered with an expected error threshold set to 1 per sequence.

Sequences were dereplicated and unique sequences with fewer than 4 reads were discarded, then all unique sequence reads were sorted by their respective frequencies. Unique reads with $97 \%$ similarity were clustered into OTUs and a representative sequence for each OTU was generated. The clustering algorithm also removed chimeras. For fungal ITS and bacterial 16S sequences, the UTAX algorithm (https://drive5.com/usearch/ manual/tax_conf.html) assigned each OTU representative sequence to taxonomic ranks by alignment with the gene sequences in the reference databases 'Unite $\mathrm{V} 7$ ' (Koljalg et al. 2013) and RDP trainset 15 (REF - RDP) (Cole et al. 2014), respectively. For $18 \mathrm{~S}$ and Oomycete ITS, the SINTAX algorithm (Edgar 2016) was used to assign taxonomy, using for both (separately) a subset of the SILVA_ssu database (Glöckner et al. 2017) covering Stramenopiles and Nematoda. Additionally, the Oomycete ITS database was combined with the Unite V7 fungal database.

\section{Statistical analysis}

All statistical analyses were conducted in R V3.4.0 ( $\mathrm{R}$ Core Development Team 2008). 


\section{Morphological data}

Datasets comprising ordinal variables (i.e. the ratings assigned by visual assessment) were analyzed by the fitting of Proportional Odds Models [a cumulative logit model] (McCullagh and Nelder 1989). Assuming $Y_{i}$ is an ordinal variable, recorded in $j$ categories, then $Y_{i}$ follows a multinomial distribution with parameter $\pi$; and $\pi_{i j}$ denotes the probability that $i$ th plant falls in the score $j$. The cumulative probability is then defined as

$$
\gamma_{i j}=P\left(Y_{i} \leq j\right)=\pi_{i 1}+\cdots+\pi_{i j}
$$

A cumulative logit is defined as:

$$
\begin{aligned}
\operatorname{logit}\left(\gamma_{i j}\right) & =\operatorname{logit}\left(P\left(Y_{i} \leq j\right)=\ln \left\{\frac{P\left(Y_{i} \leq j\right)}{1-P\left(Y_{i} \leq j\right)}\right\}\right. \\
& =\ln \left\{\frac{P\left(Y_{i} \leq j\right)}{P\left(Y_{i}>j\right)}\right\}
\end{aligned}
$$

A cumulative logit model is a regression model for a cumulative logit:

$$
\operatorname{logit}\left(\gamma_{i j}\right)=\ln \left\{\frac{P\left(Y_{i} \leq j\right)}{P\left(Y_{i}>j\right)}\right\}=\alpha_{j}-\sum \beta_{k} x_{i k}
$$

where $x_{k}$ represents the $k$ th explanatory variate, $\beta_{k}$ the effect of $x_{k}$, and $\alpha_{j}$ the intercept for each cumulative logit. The regression part $\sum \beta_{k} x_{i k}$ is independent of $j$. The larger the value of $\sum \beta_{k} x_{i k}$, the higher the probability of $Y_{i}$ falling in a category at the upper end of the category scale. $\beta$ estimates the change in the cumulative odds ratio (on a ln scale) for a single unit increase in the value of explanatory variate $x$. Deviance tests based on nested models were used to test for treatment effects, and to compare the impact of individual treatments on variables of interest. The cumulative logit model was fitted with the 'Ordinal' package for R (Haubo and Christensen 2018).

For ease of data presentation for ordinal variables, we also calculated a composite index for each treatment as: $X=\frac{\sum_{i=0}^{4} i \cdot N_{i}}{4 N}$, where $i$ is the score from 0 to $4, N_{i}$ the number of plants in the $i$ th score category, and $N$ the total number of plants for a specific treatment.

For other variables, standard analysis of variance (ANOVA) was used to test for treatment effects. Where the same variable was measured repeatedly over time during the course of the experiment, the relative rate of increase from planting to the next measurement time was calculated as $\frac{(\mathrm{x} 2-\mathrm{x} 1)}{\mathrm{x} 1}$. Then, separately for each time point, this derived rate variable was analysed via ANOVA, in which the corresponding measurement at planting time was used as a covariate.

\section{Sequence data: normalization and filtering}

OTU counts were normalised for library size using the median-of-ratios method implemented in DESeq2 (Love et al. 2014), and where appropriate transformed using the DESeq2 variance stabilisation transformation (VST). VST-transformed OTU counts were used for principal component (PCs) and redundancy analyses (RDA). All analyses were carried out separately for the fungal, nematode and oomycete datasets.

Prior to library size normalisation, samples which either failed sequencing or had very few total reads relative to other samples were removed. Post normalisation, oomycete ITS OTUs which were not assigned by SINTAX to the stramenopiles (heterokonts), alveolates, and Rhizaria (SAR) clade were excluded from all statistical analyses. Nematode OTUs which had a SINTAX confidence of less than $90 \%$ at the Order level were excluded from all statistical analyses. OTUs with fewer than 5 reads across all samples were excluded from statistical analysis (with the exception of Alpha diversity).

\section{Diversity indices}

Alpha ( $\alpha$ ) diversity (Chao1, Shannon and Simpson) indices were calculated using Vegan 2.3-1 (Dixon 2003) and the R Phyloseq 1.12.2 (McMurdie and Holmes 2013) packages. The ranks of $\alpha$-diversity indices were subjected to ANOVA to assess the differences between treatment, genotype and their interaction via a permutation of significance, where appropriate post-hoc tests were performed using Tukey's Honest Significant Difference test. Beta $(\beta)$ diversity was estimated from principal component scores. Permutation multivariate ANOVA (PERMANOVA), as implemented in $\mathrm{R}$ with Vegan 2.31 , was performed to assess the differences between genotype, treatment and their interaction.

\section{Treatment effects on community structure}

RDA was used to estimate the contributions of genotype, treatment and their interaction to the explained variation within the OTU datasets, after removal of the block effect. Statistical analysis of the overall model (Block+ Treatment + Genotype + Treatment $\times$ Genotype) to predict RDA axes was performed with PERMANOVA.

\section{Differential OTU abundance}

OTUs with differential relative abundances between each treatment and the control samples were detected by analysis with DESeq2 using raw counts datasets, without rarefication (McMurdie and Holmes 2014). OTUs were automatically filtered by a DESeq 2 algorithm, according to abundance across samples and overall abundance, 
before differential abundance analysis. The BenjaminiHochberg (BH) adjustment was applied to $\mathrm{p}$ values (Benjamin and Aikman 1995) to reduce the false discovery rate associated with multiple testing. For construction of heat trees, differential analysis also included the abundances for taxonomic ranks above OTU (species) level. The abundance for each OTU were combined at higher taxonomic ranks if the OTU could be assigned to that rank with greater than or equal to $65 \%$ confidence, otherwise the abundances were combined as unknown at that rank. Heat trees were plotted using the R metacoder package (Foster et al. 2017). We used FunGuild (Nguyen et al. 2016) to annotate the fungal OTUs with trophic mode information. Those fungal OTUs with differential abundance between control and treated samples were tested for enrichment of trophic mode using a Fisher exact test. Significance was taken at a $\mathrm{P}$ value of 0.05 and was not corrected for multiple testing.

\section{Results}

\section{Dead and diseased trees}

At termination, girdling European apple canker lesions at the graft union were evident in 12 of the 120 trees, including four dead ones. Another four trees were severely affected by other diseases, e.g. powdery mildew. For 10 of the 20 rootstock genotype $\times$ biocide treatment combinations, the number of replicates was reduced to five and for a further three treatment combinations it was reduced to four. Rootstock G.41 and M.116 were the rootstock genotypes with the greatest incidence of canker (6 and 5 trees, respectively), three trees on M.9 were affected and two on M.M.106. Thus, only 104 trees were included in further statistical analysis (Additional file 1: Table S1 presents full details of replicates for genotype $\times$ treatment).

\section{Root traits \\ Root necrosis}

Nearly $80 \%$ of trees developed root necrosis. There were 22, 41, 34, 7 and 0 trees with root necrosis scores of $0,1,2,3$ and 4, respectively. Root necrosis differed $(\mathrm{P}<0.001)$ among the five soil biocide treatments, but not among rootstock genotypes. The untreated control had the most severe root necrosis $(\beta=0$ in Eq. 3); the Nem_Oom_Fung treatment the lowest $(\beta=-3.46 \pm 0.713)$; the other three treatments did not differ from each other $(\beta=--1.25 \pm 0.502)$ and were between the two extreme treatments (Figs. 1a, 2a). The common intercept estimates are $\mathrm{a}_{0 \mid 1}=-2.97 \pm 0.703 ; \mathrm{a}_{1 \mid 2}=-0.45 \pm 0.618$ and $\mathrm{a}_{2 \mid 3}=2.33 \pm 0.705$.

\section{Lateral root abundance}

There were $0,2,20,36$ and 46 trees with lateral root abundance scores of $0,1,2,3$ and 4, respectively. Lateral root abundance was affected $(\mathrm{P}<0.001)$ by the soil biocide treatments. There was an indication $(\mathrm{P}=0.051)$ for the existence of interactions between treatments and rootstock genotypes; M.116 and M.M.106 grown on Nem_Oom_Fung treated soil had less lateral root abundance than the expected mean from the biocide amendment and genotype main effects. The overall soil biocide treatment effect followed a similar pattern as for root necrosis. The control had the least root development $(\beta=0)$; the Nem_Oom_Fung treatment had the greatest root development $\beta=2.63 \pm 0.669$ ); while the other three were between the two extremes and did not differ from each other $(\beta=0.98 \pm 0.470$, Figs. $1 b, 2 b)$. The common intercept estimates are $\mathrm{a}_{1 \mid 2}=--4.10 \pm 0.927 ; \mathrm{a}_{2 \mid 3}=$ $-1.40 \pm 0.629$ and $\mathrm{a}_{3 \mid 4}=0.43 \pm 0.616$.

\section{Crown gall}

There were 24, 3, 66, 9 and 2 trees with crown gall scores of $0,1,2,3$ and 4 , respectively. The severity of crown gall differed $(\mathrm{P}<0.001)$ among the four rootstock genotypes, but not among five soil biocide treatments. Most of the genotypic differences were due to the fact that G.41 had much less crown gall development than the other three genotypes (Fig. 1c). In addition, M.116 also had more severe crown gall development than M.9 $(\mathrm{P}<0.05)$. The parameter estimates are $\beta=0$ (G.41), $\beta=4.98 \pm 0.957$ (M.9), $\beta=5.50 \pm 1.001$ (M.M.106), and $\beta=6.97 \pm 1.084$ (M.116); the intercept estimates are $\mathrm{a}_{0 \mid 1}=3.06 \pm 1.04$, $\mathrm{a}_{1 \mid 2}=3.53 \pm 1.06 ; \mathrm{a}_{2 \mid 3}=9.03 \pm 1.46$ and $\mathrm{a}_{3 \mid 4}=11.06 \pm 1.62$.

\section{Above-ground traits}

There were no statistically significant effects of the five soil biocide treatments on any of the above-ground plant traits. However, after accounting for physical differences related to rootstock size at planting, rootstock genotype did have a statistically significant effect on the net scion height after 6 months, the number of branches, total length of branches after taking in account the number of branches, rootstock trunk girth expansion rate in the first 15 months, and rootstock trunk biomass (Table 2). For a given rootstock trunk size at month 0 , the rate of increase was greatest for M.9 and least for M.M.106 (Fig. 3).

\section{Below ground traits}

M.9 root biomass was reduced by at least $24.5 \%$ relative to M.M.116 and 33.2\% to G.41 (Table 2). Adjustment to account for rootstock girth at month 15 revealed that root biomass differed $(\mathrm{P}<0.001)$ between treatments as well as genotypes. M.9 had the least biomass, whilst there were no significant differences among G.41, M.116 and M.M.106. The untreated control, Nem_Oom and Nematicide had the least root biomass, and the Nem Oom_Fung treatment had the greatest root biomass. 

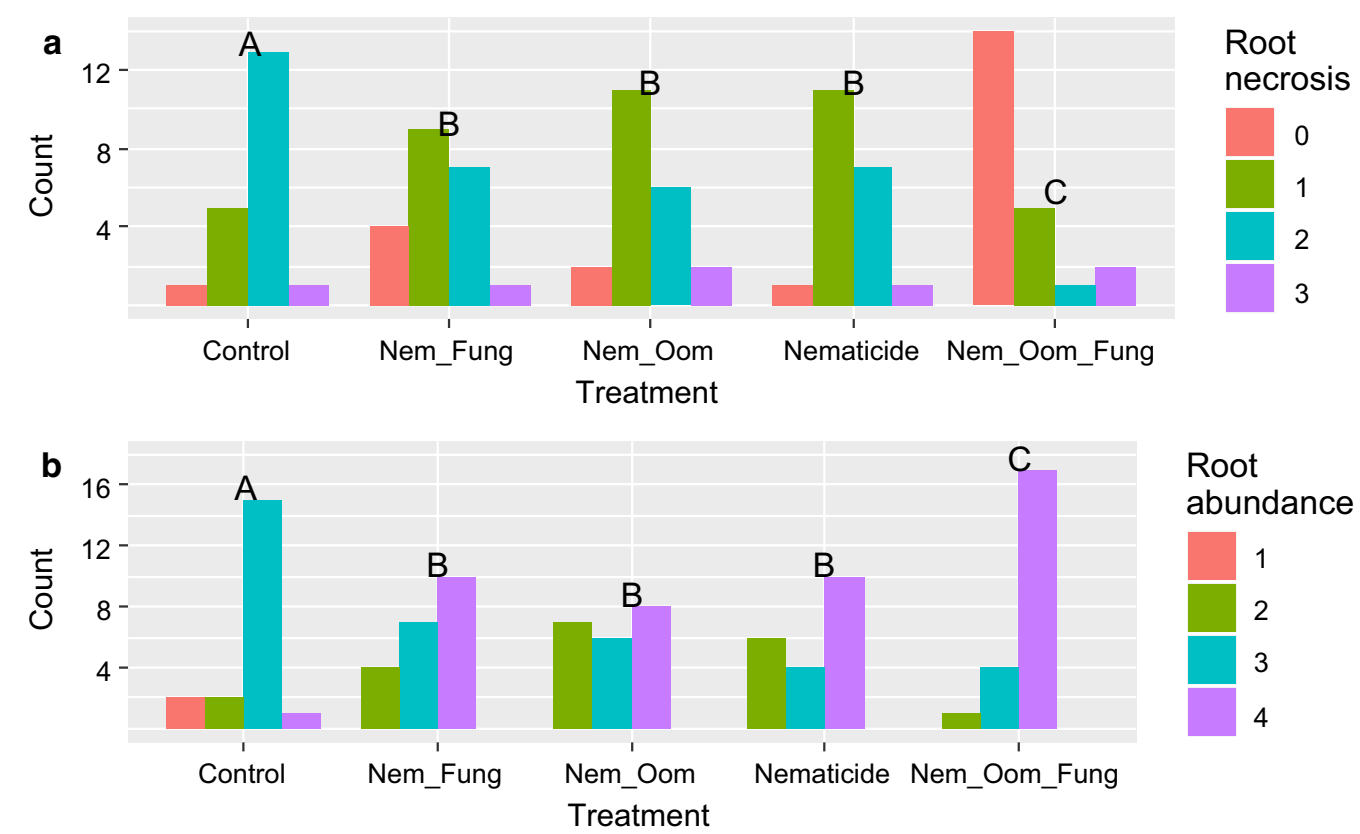

Root abundance
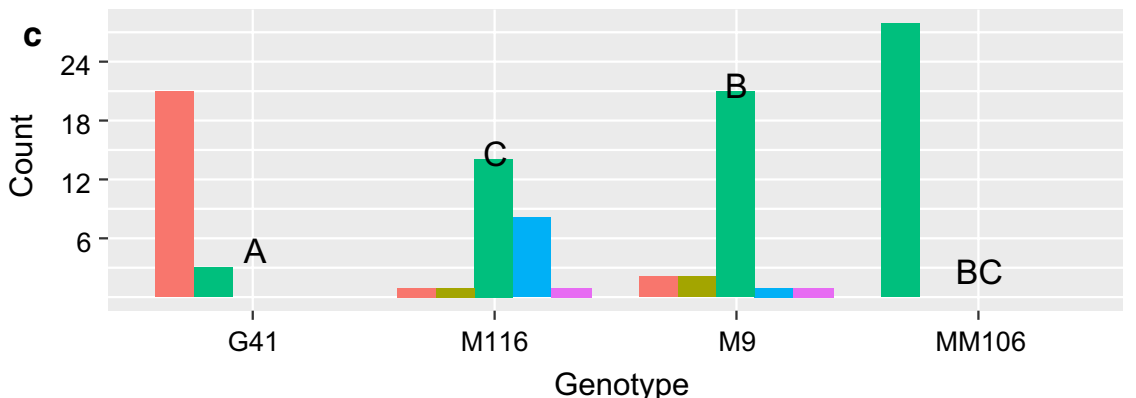

Crown gall

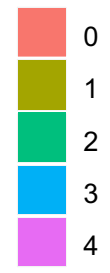

Genotype

Fig. 1 Frequency distribution of root necrosis (a), lateral root abundance (b) and crown gall (c) in relation to soil treatments or rootstock genotypes. The letter above each level of specific factors indicates pair-wise comparison results based on the deviance test of nest models in the proportional odds model: treatments sharing at least one common letter do not differ significantly $(P<0.05)$ from each other

Rootstock genotypes differed $(\mathrm{P}<0.001)$ in the crown gall biomass, after adjusting for root biomass. M.116 had the greatest crown gall biomass, and G.41 the least; M.9 had a similar crown gall biomass to M.M.106.

There were no significant relationships between rootbased and above-ground plant traits.

\section{Overview of sequence results}

Rarefaction analysis showed that the present sequencing depth was sufficient for all of the samples after primary filtering for sequence quality (Additional file 1: Fig. S1). Although there were large numbers of OTUs in all samples, only a small proportion of OTUs accounted for the majority of mapped reads. In total, there are 2046, 5837, 174 and 38 OTUs for fungi, bacteria, oomycetes and nematodes, respectively. Most fungal and bacterial OTUs were from Ascomycota and Preteobactgeria phyla, respectively (Additional file 1:
Fig. S2). Analysis of the abundance of fungal genera showed that the majority of reads could not be assigned (even with only $60 \%$ confidence) at this rank (Additional file 1: Fig. S3); although a large proportion of reads could be assigned successfully, for all treatments, to the Nectriaceae family (Additional file 1: Fig. S3).

Overall, the statistical confidence with which OTUs could be mapped onto known taxonomic units was generally very low. For example, 63.4\%, 20.1\% and $15.5 \%$ of fungal OTU representative ITS sequences could be mapped to the taxonomic rank of phylum, class and order with $\geq 90 \%$ confidence, respectively. The corresponding values for bacteria were $80.1 \%, 52.5 \%$, $18.9 \%$. The BLASTn search results of randomly selected sequences from these 'unknown' OTUs confirmed the uncertainty in assigning lower taxonomy ranks to these OTUs. In all cases, the uncertainty in assigning OTUs to specific taxonomic ranks was not associated with 


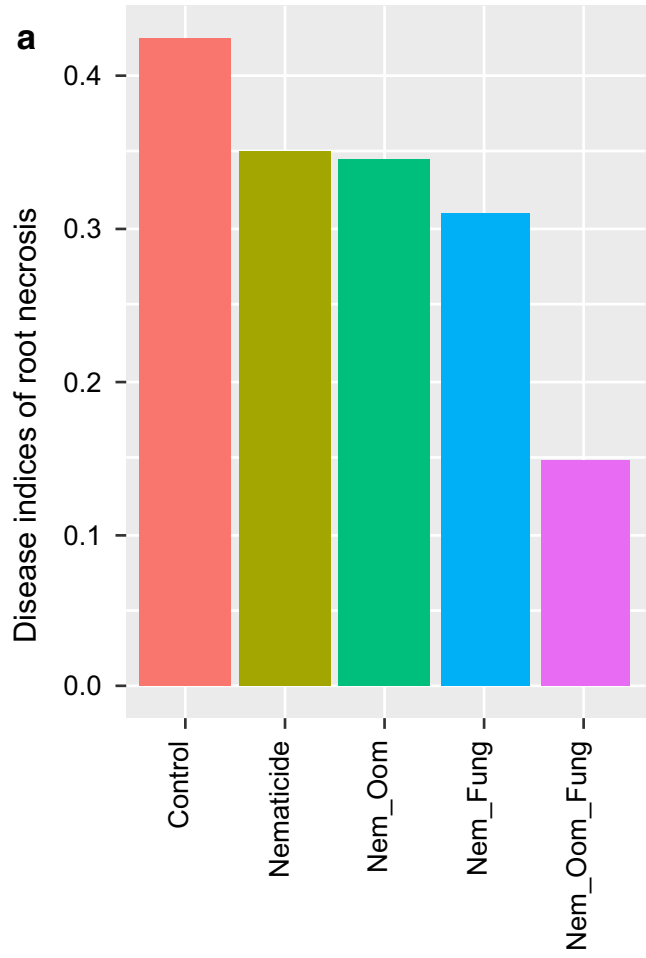

Treatment

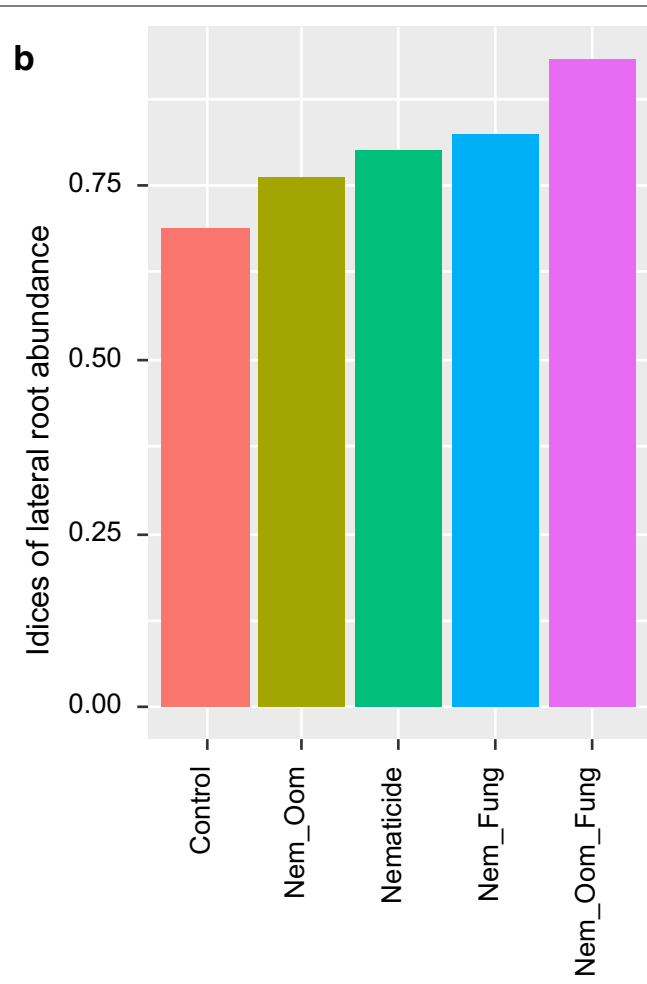

Treatment

Fig. 2 The effect of the five soil treatments on root necrosis (a) and lateral root abundance (b). Further details of both indices are provided in the text

Table 2 Selected tree traits for which there were significant differences among the four rootstock genotypes

\begin{tabular}{|c|c|c|c|c|c|c|c|c|c|c|c|c|c|c|c|}
\hline \multirow[t]{3}{*}{ Genotype } & \multicolumn{4}{|c|}{ Trunk diameter (mm) } & \multicolumn{4}{|c|}{ Trunk girth $(\mathrm{cm})$} & \multirow{2}{*}{\multicolumn{2}{|c|}{$\begin{array}{l}\text { Net scion } \\
\text { height }(\mathrm{cm})\end{array}$}} & \multirow{3}{*}{$\begin{array}{l}\text { Root } \\
\text { biomass } \\
\text { (g) } 4\end{array}$} & \multirow{3}{*}{$\begin{array}{l}\text { Rootstock } \\
\text { trunk biomass } \\
\text { (g) } 4\end{array}$} & \multirow{3}{*}{$\begin{array}{l}\text { Scion } \\
\text { biomass } \\
\text { (g) }\end{array}$} & \multirow{3}{*}{$\begin{array}{l}\text { Number } \\
\text { of branches }\end{array}$} & \multirow{3}{*}{$\begin{array}{l}\text { Total branch } \\
\text { length } \\
(\mathrm{mm})^{5}\end{array}$} \\
\hline & \multicolumn{2}{|c|}{ Rootstock } & \multicolumn{2}{|c|}{ Scion } & \multicolumn{2}{|c|}{ Rootstock } & \multicolumn{2}{|c|}{ Scion } & & & & & & & \\
\hline & $M 6^{1}$ & $\mathrm{M} 15^{1,2}$ & M6 & M15 & M6 & $\overline{M 15}$ & M6 & M15 & $M 6^{3}$ & M15 & & & & & \\
\hline G.41 & 10.8 & $14.3 b^{6}$ & 8.9 & 11.8 & 3.5 & 4.9 & 2.8 & 4.1 & $79.9 a$ & 132.7 & $27.7 b$ & $30.3 c$ & 83.8 & $9.6 c$ & $128.2 \mathrm{a}$ \\
\hline M.116 & 10.1 & $13.4 \mathrm{C}$ & 8.7 & 11.9 & 3.3 & 4.7 & 2.2 & 4.2 & $66.7 b$ & 128.8 & $26.1 b$ & $26.9 a$ & 85.8 & $8.8 b$ & $160.6 c$ \\
\hline M.9 & 10.6 & $14.8 \mathrm{a}$ & 8.9 & 11.4 & 3.4 & 5.0 & 2.7 & 4.1 & $64.9 b$ & 128.0 & $20.8 a$ & $29.9 b$ & 84.4 & $6.8 \mathrm{a}$ & 108.0a \\
\hline M.M.106 & 10.5 & $13.3 c$ & 8.7 & 11.8 & 3.3 & 4.7 & 2.7 & 4.1 & $72.6 c$ & 132.3 & $25.9 b$ & $32.5 c$ & 85.2 & $8.3 b$ & $142.2 b$ \\
\hline
\end{tabular}

1 Values are means of measurements made 6 and 15 months (M6 and M15, respectively) after planting, unless otherwise indicated

2 The rate of trunk diameter increase between month 0 and 15, namely (TD15-TD0)/TD0, and trunk diameter at month 0 used as a covariate

${ }^{3}$ The rate of net height increase between month 0 and 8, namely (NH8-NH0)/NHO

${ }^{4}$ The rootstock trunk girth at month 15 was used as a covariate

${ }^{5}$ Significance was for branch length when the number of branches was used as a covariate

${ }^{6}$ Treatments with the different low case letters differed significantly at $P=0.05$ based on the nest-model comparisons

the sample status (rootstock genotypes or soil biocide treatments).

Additional file 1: Table S3 lists, per soil amendment, the frequency of fungal and oomycete genera containing plant pathogenic species believed to be involved in ARD. Plant pathogenic nematodes are also given although none is known to be associated with ARD. The Oomycetes were dominated by Pythium species, with frequency of other pathogens comparatively much lower. The relative level of Fusarium fungi was much higher in the control samples (Additional file 1: Table S3, Fig. S3). No fungi of the Rhizoctonia genus were present in any samples. 


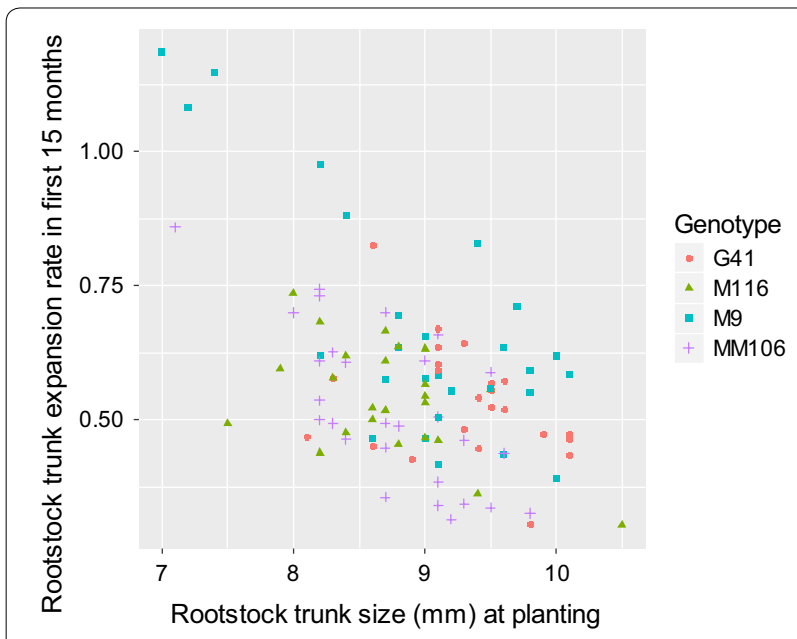

Fig. 3 The relative expansion rate of rootstock trunk girth of the four rootstock genotypes within the first 15 months of their development in relation to the size at the planting time
Nematodes were dominated by a single species in the Cephalobus genus.

\section{Rhizosphere microbial community diversity}

Alpha diversity was very variable between samples; bacterial alpha diversity indices are shown in Fig. 4 as an example; similar alpha diversity results were obtained for fungi, oomycetes and nematodes. In all cases, there were no significant interactions between soil biocide treatment and rootstock in affecting alpha diversity indices (Table 3). For bacteria, oomycetes and nematodes, the soil biocide treatments had a greater effect on alpha diversity indices than rootstock genotypes (Table 3 ). In contrast, none of the fungal alpha diversity indices was affected by soil biocide treatments, but the Shannon and Simpson indices were affected by rootstock genotypes (Table 3); M.9 was significantly different from the other genotypes for both metrics (Additional file 1: Fig. S4).
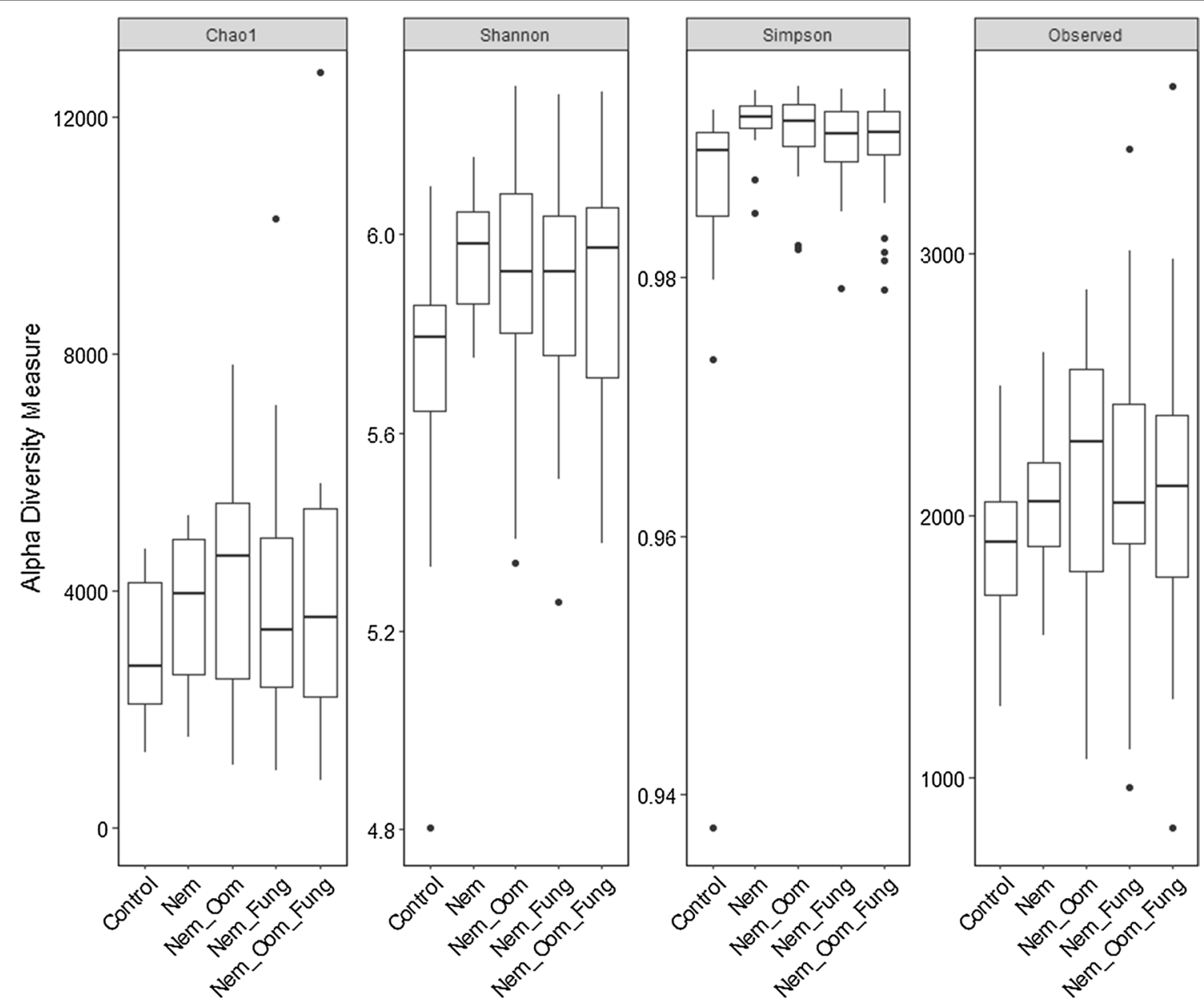

\section{Soil treatment}

Fig. 4 Alpha diversity indices and the observed number of OTUs for bacteria in relation to the five soil treatments over the four rootstock genotypes. The Chao 1 plot has been limited to 12,500 on the $y$-axis to remove several extreme outliers 
Table 3 Summary of permutation (1000 times) ANOVA results [percentage of variance (\%) accounted for, and the associated $p$ values $(<0.05$ highlighted in italics)] for alpha diversity

\begin{tabular}{|c|c|c|c|c|c|c|c|}
\hline \multirow[t]{2}{*}{ Indices } & \multicolumn{2}{|l|}{ Treatment } & \multicolumn{2}{|l|}{ Genotype } & \multicolumn{2}{|l|}{ Interaction } & \multirow{2}{*}{$\begin{array}{l}\text { Residual } \\
\%\end{array}$} \\
\hline & $\%$ & $p$ & $\%$ & $p$ & $\%$ & $p$ & \\
\hline \multicolumn{8}{|l|}{ Bacteria } \\
\hline Chaol & 2.31 & 0.640 & 1.61 & 0.935 & 7.08 & 0.773 & 85.40 \\
\hline Shannon & 12.47 & 0.005 & 7.03 & 0.025 & 2.87 & 0.999 & 74.14 \\
\hline Simpson & 14.47 & $<0.001$ & 3.47 & 0.282 & 3.18 & 0.984 & 71.71 \\
\hline \multicolumn{8}{|l|}{ Fungi } \\
\hline Chaol & 6.64 & 0.189 & 4.47 & 0.135 & 3.90 & 0.973 & 77.74 \\
\hline Shannon & 3.21 & 0.480 & 12.89 & $<0.001$ & 4.93 & 0.736 & 62.60 \\
\hline Simpson & 2.48 & 0.410 & 9.87 & $<0.001$ & 5.08 & 0.679 & 66.40 \\
\hline \multicolumn{8}{|l|}{ Oomycetes } \\
\hline Chaol & 3.52 & 0.350 & 14.01 & $<0.001$ & 6.76 & 0.576 & 64.55 \\
\hline Shannon & 9.27 & 0.004 & 3.37 & 0.303 & 9.64 & 0.390 & 68.63 \\
\hline Simpson & 10.49 & 0.005 & 3.37 & 0.163 & 8.92 & 0.500 & 68.62 \\
\hline \multicolumn{8}{|l|}{ Nematodes } \\
\hline Chaol & 7.54 & 0.059 & 8.07 & 0.028 & 6.92 & 0.788 & 66.22 \\
\hline Shannon & 14.40 & $<0.001$ & 5.10 & 0.049 & 7.03 & 0.683 & 64.64 \\
\hline Simpson & 12.58 & 0.007 & 4.66 & 0.096 & 7.46 & 0.480 & 65.84 \\
\hline
\end{tabular}

ANOVA based on the rank of individual sample alpha diversity, treatment factors are the soil treatment and rootstock genotypes

Similar to the impact on alpha diversity, for beta diversity there was no evidence for differences between samples caused by the interactions between soil biocide treatment and rootstock genotype (Table 4). Except for soil biocide treatment related effects on oomycetes, both soil biocide treatment and rootstock genotype affected beta-diversity, but they only accounted for a very small proportion of the total variation (Table 4). After removal of the block effect, partial RDA revealed latent differences in the structures of fungal, oomycete, nematode and bacterial communities related to both soil biocide treatment and rootstock genotype (Additional file 1: Fig. S5). Generally, axis 1 separated the datasets according to soil biocide treatment and axis 2 by genotype; these relationships are particularly evident for fungi and less so for the other taxa. The fungal communities associated with M.9 and G.41 rootstocks were similar to one another, as were those associated with M.M.106 and M.116 (Additional file 1: Fig. S5A). There were equivalent effects of soil biocide treatments, where treatments containing fungicides had a greater impact on fungal community structure than those that did not, and this effect was consistent across all rootstock genotypes (Additional file 1: Fig. S5B). Soil biocide treatment effects on the other target biota were subtle and were often limited to a specific rootstock genotype e.g. M.116 for the nematode community in nematicide containing treatments (Additional file 1: Fig. S6), or were under the additional influence of axis 2 e.g. M.9 for the Oomycete community in oomyceticide containing treatments (Additional file 1: Fig. S7).
Although bacteria were non-target biota of the soil biocide treatments, the structure of bacterial communities associated with G.41 and M.9 showed soil biocide treatment responses; the latter only under the additional influence of axis 2 (Additional file 1: Fig. S8).

\section{Differential abundance analysis}

The DESeq2 default criteria filtered out the majority of OTUs before statistical comparison (Table 5); for instance, only about a quarter of fungal OTUs were retained for treatment comparisons. The relative abundance of about $6 \%$ of retained fungal OTUs differed $(\mathrm{P}<0.05)$ between treated soils and the untreated control (Table 5). Forty-seven out of 72 unique OTUs with differential relative abundance were less abundant in treated soils, with treatments without fungicide having proportionally more less- abundant OTUs (Table 5, Fig. 6). The effect of fungicide treatment on OTU abundance was across multiple phyla and additional treatments (oomycide) had moderate effect on this distribution (Fig. 5).

For bacteria, treatments containing fungicides resulted in a greater proportion of OTUs with differential relative abundance (Table 5): 9.1\% (Nem_Fung) and 17.2\% (Nem_ Oom_Fung), compared with 4.0\% (Nem_Oom) and 0.2\% (Nematicide). For Nem_Oom and Nem_Fung_Oom, more OTUs (315 out of 547) had increased bacterial abundance over the control. Comparison of heat trees for the different treatments suggests a synergistic effect 
Table 4 Summary of permutation (1000 times) MANOVA results [percentage of variance (\%) accounted for, and the associated $p$ values $(<0.05$ highlighted in italics $)]$ of beta diversity

\begin{tabular}{|c|c|c|c|c|c|c|c|c|}
\hline & \multirow[t]{2}{*}{$\% \operatorname{var}^{1}$} & \multicolumn{2}{|c|}{ Soil treatment } & \multicolumn{2}{|c|}{ Genotype } & \multicolumn{2}{|c|}{ Interaction } & \multirow[t]{2}{*}{ Residual } \\
\hline & & $\%$ & $\mathrm{p}$ & $\%$ & $\mathrm{p}$ & $\%$ & $\mathrm{p}$ & \\
\hline \multicolumn{9}{|c|}{ Bacteria } \\
\hline PC1 & 10.46 & 17.66 & $<0.001$ & 3.90 & 0.153 & 7.72 & 0.560 & 68.00 \\
\hline PC2 & 7.00 & 6.79 & 0.075 & 0.80 & 0.791 & 5.70 & 0.825 & 72.64 \\
\hline PC3 & 4.15 & 4.53 & 0.183 & 9.69 & 0.005 & 2.90 & 0.980 & 66.93 \\
\hline $\mathrm{RDA}^{2}$ & & 6.67 & 0.001 & 4.24 & 0.001 & 8.80 & 0.875 & 73.72 \\
\hline \multicolumn{9}{|l|}{ Fungi } \\
\hline PC1 & 5.20 & 3.47 & 0.372 & 4.33 & 0.241 & 4.63 & 0.714 & 61.28 \\
\hline PC2 & 3.74 & 3.40 & 0.167 & 11.57 & 0.002 & 7.09 & 0.397 & 50.95 \\
\hline PC3 & 2.86 & 62.86 & $<0.001$ & 0.83 & 0.444 & 2.33 & 0.933 & 30.26 \\
\hline $\mathrm{RDA}^{2}$ & & 4.83 & 0.001 & 3.68 & 0.001 & 9.15 & 0.954 & 75.77 \\
\hline \multicolumn{9}{|c|}{ Oomycetes } \\
\hline PC1 & 8.01 & 0.75 & 0.811 & 8.16 & 0.008 & 6.06 & 0.694 & 69.61 \\
\hline PC2 & 5.27 & 2.00 & 0.526 & 13.64 & $<0.001$ & 3.54 & 0.968 & 63.07 \\
\hline PC3 & 4.52 & 4.48 & 0.182 & 2.72 & 0.278 & 12.19 & 0.215 & 65.05 \\
\hline $\mathrm{RDA}^{2}$ & & 2.90 & 0.869 & 3.91 & 0.001 & 9.12 & 0.85 & 77.02 \\
\hline \multicolumn{9}{|c|}{ Nematodes } \\
\hline PC1 & 20.21 & 13.08 & 0.003 & 7.82 & 0.015 & 11.46 & 0.184 & 64.41 \\
\hline PC2 & 11.57 & 3.08 & 0.532 & 6.94 & 0.048 & 10.62 & 0.357 & 74.66 \\
\hline PC3 & 10.34 & 7.94 & 0.039 & 7.90 & 0.023 & 6.29 & 0.753 & 65.16 \\
\hline $\mathrm{RDA}^{2}$ & & 6.85 & 0.001 & 5.05 & 0.001 & 11.01 & 0.19 & 72.20 \\
\hline
\end{tabular}

1 Percentage of variation accounted for the specific principal component (PC)

2 Overall model significant at $\mathrm{p}=0.001$ level

Table 5 The number of OTUs for which the abundance was significantly different between specific soil treatments and the untreated control for each soil treatment as determined by DESeq 2 analysis

\begin{tabular}{lrrrr}
\hline Treatment & \multicolumn{1}{l}{ Fungi } & \multicolumn{1}{c}{ Bacteria } & Oomycetes & Nematodes \\
\hline Nem_Fung & $434,13,14^{1}$ & $2291,103,116$ & $55,2,5$ & $22,3,0$ \\
Nem_Oom & $464,25,6$ & $1961,25,53$ & $65,5,5$ & $22,4,0$ \\
Nem_Oom_ & $435,17,14$ & $2723,187,282$ & $55,10,6$ & $22,2,0$ \\
$\quad$ Fung & & & & \\
Nem & $551,17,8$ & $5733,11,0$ & $76,3,5$ & $22,2,0$ \\
Total OTUs & 2046 & 5837 & 174 & 38 \\
\hline
\end{tabular}

${ }^{1}$ The first number is the number of OTUs after DeSeq2 filtering (hence compared between treatments); the second number is the number of OTUs whose relative abundance is significantly $(p<0.05)$ less in the treated than in the untreated soil; the third number is the number of OTUs whose relative abundance is significantly $(p<0.05)$ greater in the treated than in the untreated soil

between fungicide and oomycide on differentially abundant bacterial taxa (Fig. 6).

For oomycetes, the Nem_Oom_Fung treatment resulted in more OTUs with differential abundance (Table 5): $29.1 \%$, compared to $15.4 \%$ (Nem_Oom), $12.7 \%$ (Nem_Fung) and $10.1 \%$ (nematicide). The relative abundance of several nematode OTUs was reduced, but none were increased when compared with the untreated control (Table 5).

None of the fungal, oomycetes and nematode OTUs with differential abundance relative to the control is a known apple pathogen or parasite. Several fungal OTUs for Glomeromycota (mycorrhizal fungi) had differential abundance, but they showed no consistent treatment responses. Enrichment analysis of trophic mode for differential OTUs with decreased abundance was inconclusive, with more modes being affected by the nematicide only treatment (Additional file 1 : Table S4). For increased abundance OTUs, the combined nematicide, fungicide and oomycide treatment had significantly more saprotrophs/symbiotrophs than expected (Additional file 1: Table S5).

\section{Discussion}

Causal agents for ARD include several fungal species, e.g. Cylindrocarpon, Rhizoctonia, and Fusarium spp. (Mazzola and Manici 2012; Manici et al. 2013; Braun 1995; Tewoldemedhin et al. 2011a, b, c), often in conjunction with Oomycetes, including Pythium spp. (Mazzola et al. 2002; Braun 1991, 1995; Tewoldemedhin et al. 


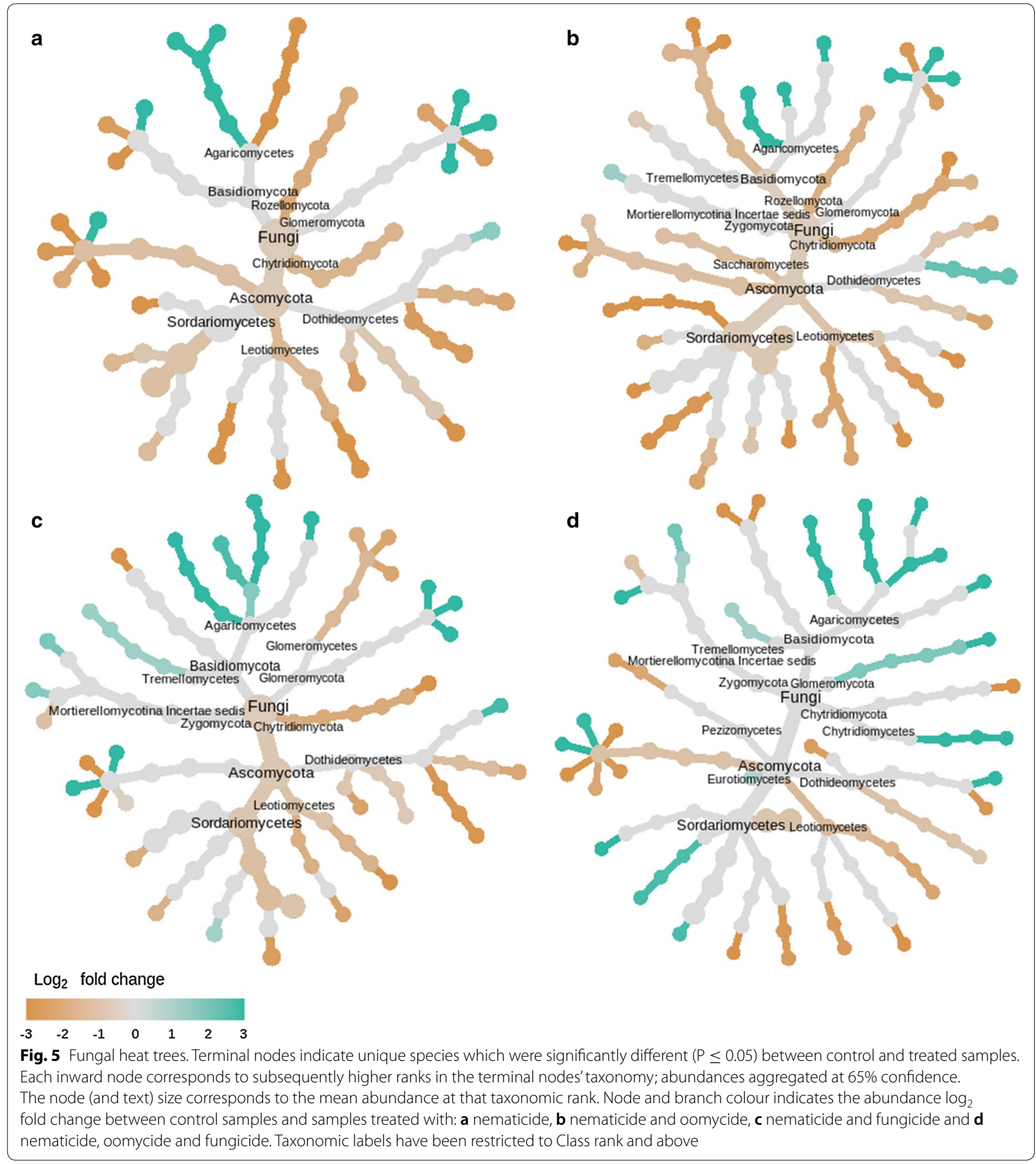

2011a, b, c). In addition, root lesions caused by nematodes, including $P$. penetrans, have been implicated in exacerbating ARD by facilitating pathogen entry into the host's root tissues (Galkovskyi et al. 2012; Mai and Abawi 1978; Tewoldemedhin, Mazzola, Labuschagne, et al. 2011a, b, c). The relative importance of these putative causal agents of ARD appears to be site-specific (Manici et al. 2013), leading to highly variable results for specific disease management strategies. Poor understanding of how these individual ARD components 


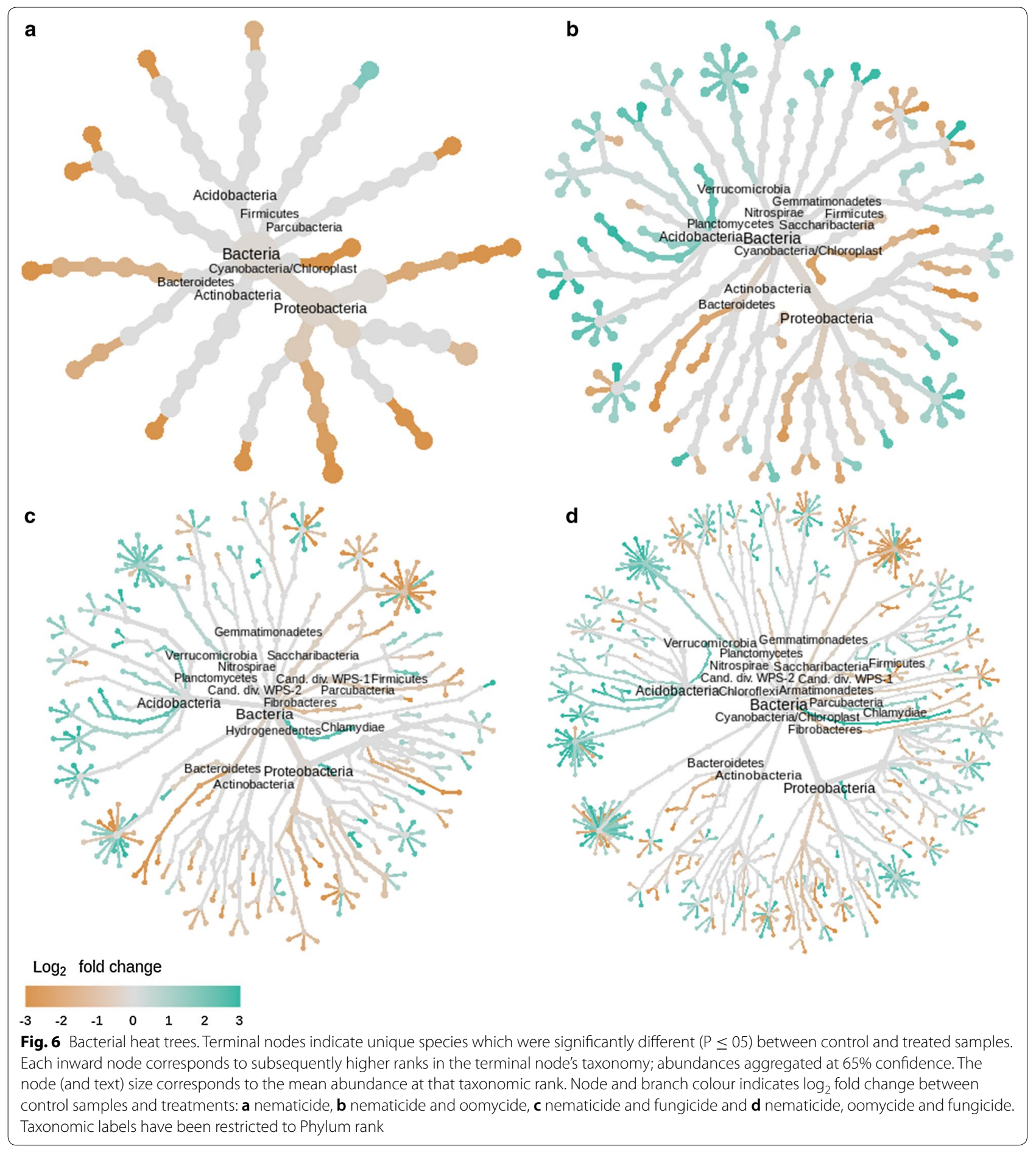

interact with each other to affect tree growth hinders the implementation of effective management strategies. Consequently, it is difficult to study the interactions between ARD components by conducting inoculation experiments with either individual, or combinations of, ARD causal agents.
In the present study, we used selective biocides to minimise/eliminate specific ARD components and studied the interactive effects of fungal and oomycete pathogens on apple tree growth and root production. No significant improvement in plant growth was observed in response to application of the nematicide. 
This may be due to the fact that $P$. penetrans was not present (or its level was extremely low) in the test soil as no reads were aligned to $P$. penetrans at the $97 \%$ similarity. However, this should not affect our interpretation of the results on the use of the oomycete biocide and fungicides. For interpretation of the results, we need to assume that each biocide had effectively reduced the size of specific pathogenic/parasitic populations, which is supported by the improved root development in these treatments. Both oomycete and fungal pathogens appeared to have equal importance as ARD causal agents in the soil used, because both Nem_Fung and Nem_Oom soil biocide treatments led to significant reductions in lateral root abundance and increased root necrosis. The importance of these two groups of pathogens is further supported by the fact that the greatest amount of root biomass was associated with the Nem_Oom_Fung treatment. In addition, the present results suggest there are competitive, rather than additive or synergistic, interactions between oomycete and fungal pathogens. Neither the severity of root necrosis, nor reductions in lateral root development, were increased in the presence of both types of pathogen relative to the effects of a single pathogen type, i.e. Nematicide vs Nem_Fung or Nem_Oom. Interspecific competitive interactions (i.e. antagonism) have often been observed in biocontrol experiments where the disease control efficacy achieved by the combined use of two biocontrol agents is less than that expected based on the control achieved by each agent alone (Xu et al. 2011). An alternative explanation is that the defence response of the plant host is independent of the number of disease-inducing pathogen categories. Thus, it is the host's defence response that ensures a similar extent of disease development, and not the competitive interactions between the initial inducers. Further studies, especially inoculation studies with more replicates, are necessary to test these hypotheses.

None of the above-ground plant traits was significantly affected by any of the soil biocide treatments, but some above-ground traits were significantly influenced by rootstock genotype. As expected, the (semi-)dwarfing rootstocks M.9 and G.41 gave rise to above-ground traits that had greater similarity with each other than with M.116 and M.M.106. In replant orchards, root necrosis and reduced lateral root abundance are frequently associated with reduced above-ground tree development, but the 15-month duration in the present study may not have been long enough for reductions in above-ground growth and development to be detected in response to specific soil biocide treatments. Also, the fertigated pot-based growing system may have ameliorated physiological stress experienced by the trees with the smallest root systems and the most root necrosis, and facilitated greater tolerance of infection than would be possible in unprotected orchard plantings.

Apple rootstock genotypes differ in their responses to ARD (Fazio et al. 2012), and although the dwarfing rootstock M.9 has been instrumental in the development of the high density planting systems used in dessert apple production, it is also severely affected by ARD (Auvil et al. 2011). Semi-dwarfing rootstocks, such as 'M.M.106', 'M.M.111', and more recently 'M.116', are typically used in cider orchards in the UK where they show variable levels of susceptibility to ARD (Auvil et al. 2011; St. Laurent 2008; Wilcox 1990). G.41 is another recently bred rootstock and has reported tolerance to ARD (Fazio et al. 2012). Interestingly, G.41 had near zero incidence of crown gall, which was significantly less than the crown gall incidence observed in the other three rootstock genotypes. Further research is needed to understand whether there is an interaction between resistance to crown gall development and ARD tolerance.

The effects of soil biocide treatments on soil microbiota persisted over the study duration (15 months), particularly for bacteria and nematodes. For fungi, biocide treatment did not have an apparent effect on the within-sample diversity indices (i.e. alpha diversity) after 15 months. In contrast, bacterial alpha diversity differed greatly among samples, even after 15 months; but with little difference in the sample-to-sample differences (beta-diversity). The overall differences in the community structure, 15 months after treatment, generally agree with the treatment. Thus, the differences in fungal abundance and diversity were mainly between treatments with, or without fungicides. These results suggest that both fungi and oomycetes may recover more quickly, after the application of selective biocides, than bacteria and nematodes. Another explanation is that the three biocides used against fungi and oomycetes primarily affected pathogens (as shown by the effect on root development), which did not result in much changes in the overall fungal/oomycete community structure. However, this second explanation is probably far less plausible as recent research suggested that pesticides can significantly alter the soil microbiome (Fournier et al. 2020; Wang et al. 2020). Interestingly, although bacteria were not the direct target of the soil biocide treatments, their community structure was profoundly affected, even 15 months after treatment.

Statistical analysis identified a number of OTUs in each group of organisms which had differential abundance between individual treatments and the untreated control. However, none of these OTUs with differential abundance can be confidently confirmed as an apple root pathogen or parasite, because of the nature of the 
'universal' (barcoding) primers used. It is also possible that any statistically significant differences between the treated and the untreated control for the relative abundance for specific pathogens/parasites present at the outset did not persist until termination 15 months after treatment. However, it is in the early stages of the experiment, when the roots of young plants are assumed to have been most susceptible to pathogen attack, that differences in pathogenic groups would have had the greatest impact on the observed differences in root necrosis and abundance. The majority of bacterial OTUs where relative abundance was increased, compared with the untreated control, were obtained from treatments containing the fungicide and/or oomycete biocide, which agrees with our recent finding that the relative bacterial OTU abundance is generally greater in the rhizosphere of healthy trees, than in ARD-affected trees (Tilston et al. 2018). In contrast, the treatment which resulted in the fewest changes in abundance within the bacterial community was the nematicide only treatment. Together these effects suggest that bacteria utilised the fungal and oomycete necromass as a source of carbon and nitrogen, resulting in a general increase in bacterial abundance (Brabcová et al. 2016). The biocide compounds could also serve as an additional carbon source in these systems.

\section{Conclusions}

We demonstrated that competitive interactions between oomycetes and fungal pathogens might occur during the infection of apple roots and continue during subsequent ARD development. Controlling all three ARD components (oomycetes, fungi, and nematodes) led to the production of most root biomass and the least amount of root necrosis. However, these effects on root systems were not translated into enhanced above-ground tree development within 15 months after treatment. The effects of soil biocide treatments on bacteria and nematodes persisted longer than on fungi.

\section{Supplementary information}

Supplementary information accompanies this paper at https://doi. org/10.1186/s43170-020-00014-7.

Additional file 1. Additional tables.

\section{Acknowledgements}

We thank Dr Helen Cockerton for providing us with the primers to amplify segments of nematode DNA. The authors wish to thank Dr Flora O'Brien for technical assistance with the amplicon sequencing.

\section{Authors' contributions}

$\mathrm{XX}$ is the corresponding author and primary contact during manuscript submission, review, and publication process. The work was done under his supervision as the principal investigator. He significantly contributed to the design, drafting the manuscript, and interpretation of data. XX is the submitting author. XX, NH, FF and ELT designed the study. ELT, JB and TP conducted the experiments. GD analysed the data. ELT, GD and XX prepared the manuscript for submission. All authors read and approved the final manuscript.

\section{Funding}

This research is funded by BBSRC (grant number: BB/M01777X/1) and a consortium of industry partners: HEINEKEN UK Limited, Frank P. Matthews, Fruittree Rootstock Holland B.V., Vermeerderingstuinen Nederland, and A.C. Goatham \& Son

\section{Availability of data and materials}

The data will be made available upon request. Although experimental materials had been destroyed, rootstock and scion cultivars as well as soil amendment products are available commercially.

\section{Ethics approval and consent to participate}

Not applicable.

\section{Consent for publication \\ Not applicable.}

\section{Competing interests}

The authors declare that the research was conducted in the absence of any commercial or financial relationships that could be construed as a potential conflict of interest.

Received: 28 May 2020 Accepted: 24 September 2020

Published online: 07 October 2020

\section{References}

Auvil TD, Schmidt TR, Hanrahan I, Castillo F, McFerson JR, Fazio G. Evaluation of dwarfing rootstocks in Washington apple replant sites. Acta Hort. 2011;903:265-71.

Benjamin LR, Aikman DP. Predicting growth in stands of mixed species from that in individual species. Ann Bot. 1995;76:31-41.

Brabcová V, Nováková M, Davidová A, Baldrian P. Dead fungal mycelium in forest soil represents a decomposition hotspot and a habitat for a specific microbial community. New Phytol. 2016;210:1369-81. https://doi. org/10.1111/nph.13849.

Braun PG. Effects of Cylindrocarpon and Pythium species on apple seedlings and potential role in apple replant disease. Can J Plant Pathol. 1995;17:336-41. https://doi.org/10.1080/07060669509500672.

Braun PG. The combination of Cylindrocarpon lucidum and Pythium irregulare as a possible cause of apple replant disease in Nova Scotia. Can J Plant Pathol. 1991;13:291-7. https://doi.org/10.1080/07060669109500914.

Cole JR, Wang Q, Fish JA, Chai B, McGarrell DM, Sun Y, et al. Ribosomal Database Project: data and tools for high throughput rRNA analysis. Nucleic Acids Res. 2014;42:D633-D642642.

Cooke DEL, Duncan JM. Phylogenetic analysis of Phytophthora species based on ITS1 and ITS2 sequences of the ribosomal RNA gene repeat. Mycol Res. 1997;101:667-77.

Deakin G, Tilston EL, Bennett J, Passey T, Harrison N, Fernández-Fernández F, et al. Spatial structuring of soil microbial communities in commercial apple orchards. Appl Soil Ecol. 2018;130:1-12.

Dixon P. VEGAN, a package of R functions for community ecology. J Veg Sci. 2003;14:927-30. https://doi.org/10.1111/j.1654-1103.2003.tb02228.x.

Dullahide S, Stirling G, Nikulin A, Stirling A. The role of nematodes, fungi, bacteria, and abiotic factors in the etiology of apple replant problems in the Granite Belt of Queensland. Aust J Exp Agric. 1994;34:1177. https://www. publish.csiro.au/?paper=EA9941177. Accessed 12 Dec 2018.

Edgar R. SINTAX: a simple non-Bayesian taxonomy classifier for $16 \mathrm{~S}$ and ITS sequences. bioRxiv. 2016. https://www.biorxiv.org/content/biorxiv/early /2016/09/09/074161.full.pdf.

Edgar RC. UPARSE: highly accurate OTU sequences from microbial amplicon reads. Nat Methods. 2013;10:996-8. https://doi.org/10.1038/nmeth.2604.

Edgar RC, Flyvbjerg H. Error filtering, pair assembly and error correction for next-generation sequencing reads. Bioinformatics. 2015;31:3476-82. 
FAO, and IUSS. World reference base for soil resources 2014: international soil classification system for naming soils and creating legends for soil maps -update 2015. Rome: FAO. 2015. https://www.fao.org/publications/card/ en/c/942e424c-85a9-411d-a739-22d5f8b6cc41/. Accessed 9 May 2018.

Fazio G, Kviklys D, Grusak MA, Robinson T, Genetics P, Unit R. Soil pH, soil type and replant disease affect growth and nutrient absorption of apple rootstocks. New York State Hortic Soc. 2012;20:22-28. https://nyshs.org/ wp-content/uploads/2016/10/5.Soil-pH-Soil-Type-and-Replant-Disea se-Affect-Growth-and-Nutrient-Absorption-of-Apple-Rootstocks.pdf. Accessed 13 Dec 2018.

Floyd RM, Rogers AD, Lambshead PJD, Smith CR. Nematode-specific PCR primers for the 18S small subunit rRNA gene. Mol Ecol Notes. 2005;5:611-2. https://doi.org/10.1111/j.1471-8286.2005.01009.x.

Foster ZL, Sharpton TJ, Grunwald NJ. Metacoder: An R package for visualization and manipulation of community taxonomic diversity data. Timothée Poisot. PLOS Comput Biol. 2017;13:1005404. https://doi.org/10.1371/ journal.pcbi.1005404.

Fournier B, Pereira Dos Santos S, Gustavsen JA, Imfeld G, Lamy F, Mitchell EAD, et al. Impact of a synthetic fungicide (fosetyl-Al and propamocarb-hydrochloride) and a biopesticide (Clonostachys rosea) on soil bacterial, fungal, and protist communities. Sci Total Environ. 2020;738:139635.

Furneaux BS. The soils of East Malling Research Station for 1953. Rep East Malling Res Stn. 1954:60-82.

Galkovskyi T, Mileyko Y, Bucksch A, Moore B, Symonova O, Price C, et al. GiA Roots: software for the high throughput analysis of plant root system architecture. BMC Plant Biol. 2012;12:116

Gardes M, Bruns TD. ITS primers with enhanced specificity for basidiomycetes - application to the identification of mycorrhizae and rusts. Mol Ecol. 1993;2:113-8.

Glöckner FO, Yilmaz P, Quast C, Gerken J, Beccati A, Ciuprina A, et al. 25 years of serving the community with ribosomal RNA gene reference databases and tools. J Biotechnol. 2017;261:169-76.

Haubo R, Christensen B. Cumulative link models for ordinal regression with the R Package ordinal. 2018. https://www.jstatsoft.org/. Accessed 12 Dec 2018.

Herlemann DPR, Labrenz M, Jurgens K, Bertilsson S, Waniek JJ, Andersson AF. Transitions in bacterial communities along the $2000 \mathrm{~km}$ salinity gradient of the Baltic Sea. ISME J. 2011;5:1571-9. https://doi.org/10.1038/ismej .2011.41.

Hoitink HAJ, Boehm MJ. Biocontrol within the context of soil microbial communities: a substrate-dependent phenomenon. Annu Rev Phytopathol. 1999:37:427-46. https://doi.org/10.1146/annurev.phyto.37.1.427.

Horner IJ, Wilcox WF. Spatial distribution of Phytophthora cactorum in New York apple orchard soils. Phytopathology. 1996;86:1122-32.

Isutsa DK, Merwin IA. Malus germplasm varies in resistance or tolerance to apple replant disease in a mixture of new york orchard soils. Hortscience. 2000;35:262-268. https://hortsci.ashspublications.org/content/35/2/262. abstract.

Koljalg U, Nilsson RH, Abarenkov K, Tedersoo L, Taylor AF, Bahram M, et al. Towards a unified paradigm for sequence-based identification of fungi. Mol Ecol. 2013;22:5271-7.

Love MI, Huber W, Anders S. Moderated estimation of fold change and dispersion for RNA-seq data with DESeq2. Genome Biol. 2014;15:550. https:// doi.org/10.1186/s13059-014-0550-8.

Mai WF, Abawi GS. Determining the cause and extent of apple, cherry, and pear replant diseases under controlled conditions. Phytopathology. 1978;68:1540-44. https://www.apsnet.org/publications/phytopathology/ backissues/Documents/1978Articles/Phyto68n11_1540.PDF. Accessed 1 May 2018.

Manici LM, Kelderer M, Franke-Whittle IH, Rühmer T, Baab G, Nicoletti F, et al. Relationship between root-endophytic microbial communities and replant disease in specialized apple growing areas in Europe. Appl Soi Ecol. 2013;72:207-14.

Mazzola M, Andrews PK, Reganold JP, Lévesque CA. Frequency, virulence, and metalaxyl sensitivity of Pythium spp. isolated from apple roots under conventional and organic production systems. Plant Dis. 2002;86:669-75. https://doi.org/10.1094/PDIS.2002.86.6.669.

Mazzola M, Brown J, Zhao X, Izzo AD, Fazio G. Interaction of Brassicaceous seed meal and apple rootstock on recovery of Pythium spp. and Pratylenchus penetrans from roots grown in replant soils. Plant Dis. 2009;93:51-7. https ://doi.org/10.1094/PDIS-93-1-0051.
Mazzola M, Gu Y-H. Impact of wheat cultivation on microbial communities from replant soils and apple growth in greenhouse trials. Phytopathology. 2000;90:114-9.

Mazzola M, Manici LM. Apple replant disease: role of microbial ecology in cause and control. Annu Rev Phytopathol. 2012;50:45-65.

McCullagh P, Nelder JA. Generalized linear models. Chapman and Hall. 1989. https://www.crcpress.com/Generalized-Linear-Models/McCullagh-Nelde r/p/book/9780412317606. Accessed 12 Dec 2018.

McMurdie PJ, Holmes S. Phyloseq: an R package for reproducible interactive analysis and graphics of microbiome census data. PLoS ONE. 2013;8:e61217.

McMurdie PJ, Holmes S. Waste not, want not: Why rarefying microbiome data is inadmissible. PLoS Comput Biol. 2014;10:e1003531.

Merwin IA, Stiles WC. Root-lesion nematodes, potassium deficiency, and prior cover crops as factors in apple replant disease. J Am Soc Hortic Sci. 1989;114:724-28. https://agris.fao.org/agris-search/search.do?recor $\mathrm{dID}=\mathrm{US} 9014910$

Moriya S, Iwanami H, Takahashi S, Kotoda N, Suzaki K, Abe K. Evaluation and inheritance of crown gall resistance in apple rootstocks. J Jpn Soc Hortic Sci. 2008;77:236-241. https://joi.jlc.jst.go.jp/JST.JSTAGE/jjshs 1/77.236?from =CrossRef. Accessed 12 Dec 2018

Nguyen NH, Song Z, Bates ST, Branco S, Tedersoo L, Menke J, Schilling JS, Kennedy PG. FUNGuild: An open annotation tool for parsing fungal community datasets by ecological guild. Fungal Ecol. 2016;20:241-8.

Rumberger A, Yao S, Merwin IA, Nelson EB, Thies JE. Rootstock genotype and orchard replant position rather than soil fumigation or compost amendment determine tree growth and rhizosphere bacterial community composition in an apple replant soil. Plant Soil. 2004;264:247-60.

Russo NL, Robinson TL, Fazio G, Aldwinckle HS. Field evaluation of 64 apple rootstocks for orchard performance and fire blight resistance. Hortscience. 2007:42:1517-1525. https://hortsci.ashspublications.org/conte nt/42/7/1517.abstract.

Sequerra J, Marmeisse R, Valla G, Normand P, Capellano A, Moiroud A. Taxonomic position and intraspecific variability of the nodule forming Penicillium nodositatum inferred from RFLP analysis of the ribosomal intergenic spacer and random amplified polymorphic DNA. Mycol Res. 1997;101:465-72.

St. Laurent, A., Merwin, I. A., and Thies, J. E. 2008. Long-term orchard groundcover management systems affect soil microbial communities and apple replant disease severity. Plant Soil. 304:209-225 https://www.jstor.org/ stable/42951821.

St. Laurent A, Merwin I, Fazio G, Thies J, Brown M. Rootstock genotype succession influences apple replant disease and root-zone microbial community composition in an orchard soil. Plant Soil. 2010;337:259-72. https ://doi.org/10.1007/s11104-010-0522-z.

Tewoldemedhin YT, Mazzola M, Botha WJ, Spies CFJ, McLeod A. Characterization of fungi (Fusarium and Rhizoctonia) and oomycetes (Phytophthora and Pythium) associated with apple orchards in South Africa. Eur J Plant Pathol. 2011a;130:215-29. https://doi.org/10.1007/s10658-011-9747-9.

Tewoldemedhin YT, Mazzola M, Labuschagne I, McLeod A. A multi-phasic approach reveals that apple replant disease is caused by multiple biological agents, with some agents acting synergistically. Soil Biol Biochem. 2011b:43:1917-27.

Tewoldemedhin YT, Mazzola M, Mostert L, McLeod A. Cylindrocarpon species associated with apple tree roots in South Africa and their quantification using real-time PCR. Eur J Plant Pathol. 2011c;129:637-51. https://doi. org/10.1007/s10658-010-9728-4.

Tilston E, Deakin G, Bennett J, Passey T, Harrison N, O'Brien F, et al. Candidate causal organisms for apple replant disease in the UK. Phytobiomes J. 2018;11:18

Utkhede RS, Smith EM. Impact of chemical, biological and cultural treatments on the growth and yield of apple in replant-disease soil. Australas Plant Pathol. 2000;29:129-36.

Wang X, Lu Z, Miller H, Liu J, Hou Z, Liang S, et al. Fungicide azoxystrobin induced changes on the soil microbiome. Appl Soil Ecol. 2020;145:103343.

Webster AD, Smith RA, Watkins R. Apple rootstock studies. I. Preliminary evaluations of several MM.106 × M.27 hybrids. J Hortic Sci. 1986;61:429-37. https://doi.org/10.1080/14620316.1986.11515723. 
Weiland JE, Santamaria L, Grünwald NJ. Sensitivity of Pythium irregulare, P. sylvaticum, and $P$. ultimum from forest nurseries to mefenoxam and fosetylAl, and control of Pythium damping-off. Plant Dis. 2014;98:937-42.

White TJ, Bruns TL, Taylor JW. Amplification and direct sequencing of fungal ribosomal RNA genes for phylogentics. In: Innis MA, Gelfand DH, Snisky J J, White TJ, editors. A Guide to Molecular Methods and Applications. New York: Academic Press; 1990. p. 315-322.

Wilcox WF. Phytophthora crown, collar, and root rots. In: Jones AL, Aldwinckle HS, editors. Compendium of apple and pear diseases. St. Paul: APS Press 1990. p. 47-48.

Willett M, Smith TJ, Peterson AB, Hinman H, Stevens RG, Ley T, et al. Growing profitable apple orchards in replant sites: an interdisciplinary team approach in Washington State. Horttechnology. 1994;4:175-181. https:// horttech.ashspublications.org/content/4/2/175.abstract.
Xu X-M, Jeffries P, Pautasso M, Jeger MJJ. Combined use of biocontrol agents to manage plant diseases in theory and practice. Phytopathology. 2011:101:1024-31.

Yao S, Merwin IA, Abawi GS, Thies JE. Soil fumigation and compost amendment alter soil microbial community composition but do not improve tree growth or yield in an apple replant site. Soil Biol Biochem. 2006;38:587-99.

\section{Publisher's Note}

Springer Nature remains neutral with regard to jurisdictional claims in published maps and institutional affiliations.
Ready to submit your research? Choose BMC and benefit from

- fast, convenient online submission

- thorough peer review by experienced researchers in your field

- rapid publication on acceptance

- support for research data, including large and complex data types

- gold Open Access which fosters wider collaboration and increased citations

- maximum visibility for your research: over 100M website views per year

At BMC, research is always in progress.

Learn more biomedcentral.com/submissions 